\title{
Total Thyroidectomy in Multinodular Goiter: An African Experience
}

\author{
Moussa Abdoulaye Ouattara ${ }^{*}$, Seydou Togo ${ }^{1}$, Ibrahima Sankaré1, Kadiatou Singaré2, \\ Sekou Koumaré ${ }^{3}$, Issa Maiga1, Allaye Ombotibé ${ }^{1}$, Jacques Saye ${ }^{1}$, Assa Traoré ${ }^{4}$, \\ Nouhoum Diani ${ }^{5}$, Zimogo Ziè Sanogo ${ }^{3}$, Sadio Yena ${ }^{1}$ \\ ${ }^{1}$ Department of Thoracic Surgery, Hospital of Mali, Bamako, Mali \\ ${ }^{2}$ Department of Otorhinolaryngology, Gabriel Touré Teaching Hospital, Bamako, Mali \\ ${ }^{3}$ Department of General Surgery "A", Point G Teaching Hospital, Bamako, Mali \\ ${ }^{4}$ Department of Endocrinology, Hospital of Mali, Bamako, Mali \\ ${ }^{5}$ Department of Anesthesia, Hospital of Mali, Bamako, Mali \\ Email: "zegouatt@yahoo.fr
}

Received 26 November 2015; accepted 22 December 2015; published 25 December 2015

Copyright (C) 2015 by authors and Scientific Research Publishing Inc.

This work is licensed under the Creative Commons Attribution International License (CC BY). http://creativecommons.org/licenses/by/4.0/

(c) (i) Open Access

\section{Abstract}

Introduction: Total thyroidectomy is an operation that involves the surgical removal of the whole thyroid gland, with the preservation of the parathyroid glands. The aim of the present study was to assess the complication rates of total thyroidectomy on benign indication and first-time thyroid surgery and investigate the early outcome after opotherapy. Materials and Methods: In this retrospective study, patients who underwent total thyroidectomy for benign multinodular goiter in the department of thoracic surgery in our Hospital from January 2012 to December 2014 were included. In postoperative time, we evaluated surgical complication, histopathological examination and opotherapy. Results: A total 53 patients underwent total thyroidectomy for multmodular goiter; they were $49(92.45 \%)$ bilateral and $4(7.55 \%)$ unilateral (recurrence). The mean age was 47 years and mean diameter of goiter was $10.75 \mathrm{~cm}$. Among the patients $88.68 \%$ were females and $\mathbf{1 1 . 3 2 \%}$ were male. Preoperative hormonal statuses were $(\mathbf{7 0 \%})$ in euthyroid and $(30 \%)$ hyperthyroid following surgery complications like transient laryngeal nerve palsy $(3.77 \%)$, transient hypocalcemia $(7.55 \%)$, hematoma $(1.9 \%)$ and wound infection $(1.9 \%)$. On histopathological examination of the surgical specimen, $5.7 \%$ were reported to be malignant. Six month following surgery $92.45 \%$ of patients was a good hormonal balance. Conclusion: Total thyroidectomy for multinodular goiter has a low morbidity and mortality; this procedure olves both the problem of recurrence of disease and reintervention. The opotherapy is doable with a good hormonal balance.

"Corresponding author.

How to cite this paper: Ouattara, M.A., Togo, S., Sankaré, I., Singaré, K., Koumaré, S., Maiga, I., Ombotibé, A., Saye, J., Traoré, A., Diani, N., Sanogo, Z.Z. and Yena, S. (2015) Total Thyroidectomy in Multinodular Goiter: An African Experience. Surgical Science, 6, 527-531. http://dx.doi.org/10.4236/ss.2015.612075 


\section{Keywords}

\section{Multi-Nodular Goiter, Total Thyroidectomy, Complication}

\section{Introduction}

Thyroid gland and its diseases are known to clinical practice since the time of Hippocrates and still an important subject of interest. Normal thyroid function is necessary for physiological activity of most organs. Nodular goiter is probably the most common endocrine problem in the world today [1]. Appropriate diagnosis and proper treatment is the need of the hour, and multinodular goiter has to be managed appropriately. Total thyroidectomy is an operation that involves the surgical removal of the whole thyroid gland, with the preservation of the parathyroid glands. Total thyroidectomy has the advantage of one-stage removal of incidental thyroid cancer and a lower risk of developing recurrent goiter [2]. The most frequent complications of total thyroidectomy and subtotal thyroidectomy are transient or permanent hypocalcaemia and recurrent nerve palsy [3] [4]. Some African authors prefer subtotal thyroidectomy for the toxic multinodular goiter or not [5] [6]. The reasons cited are among other high risk of complications and hormone replacement therapy for life. The aim of the present study was to assess the complication rates of total thyroidectomy on benign indication and first-time thyroid surgery and investigated early outcome after opotherapy.

\section{Patients and Methods}

In this retrospective analysis, we were registered 345 cases of thyroidectomy among them 53 (15.36\%) cases of total thyroidectomy in the department of thoracic surgery in our Hospital from January 2012 to December 2014. Patients who underwent total thyroidectomy for Toxic and non-toxic multinodular goiter was included in the study. Only patients who consented for surgery were included. Patients with diffuse hyperplastic goiter, solitary nodule of thyroid, Grave's, and those who were preoperative diagnosed with malignancy were also excluded from the study. The demographic properties of patients, the indications for surgery, postoperative early-stage morbidity (transient and permanent recurrent laryngeal palsy, transient and permanent hypocalcaemia, postoperative bleeding and wound site infection) and length of stay in hospital were evaluated. Thyroid function and biochemistry tests were performed on each patient. Thyroid gland examinations were done on every patient before the surgical procedure. Those patients found to have hyperthyroidism before the operation were treated with antithyroid drugs (neomercazole, propylthiouracil) at doses ranging from 20 to $40 \mathrm{mg}$ for 18 to 24 months, until they became euthyroid.

After surgery, the vocal cords of all patients were examined with indirect laryngoscopy by an otorhinolaryngology specialist. During the follow-up period, those whose vocal cord movements turned to normal were regarded as having transient recurrent laryngeal nerve palsy. When vocal palsy lasted more than six months, it was regarded as persistent palsy [7]. Serum calcium levels were determined preoperatively in all patients and on the first postoperative day. Calcium levels were re-determined on the subsequent postoperative days as necessary. Patient with hypocalcemia symptoms were treated with vitamin D and calcium replacement. Patients with hypocalcaemia symptoms lasting more than six months were accepted as having persistent hyperparathyroidism [7].

For all patients' histopathological evaluation for postoperative diagnosis were carried out. All patients were treated before hospital discharge by levothyrox drug to prevent hypothyroidism. This study was approved by the local ethics committee. For the statistical evaluation, the SPSS 18.0 for Windows (SPSS inc. Chicago, Il, USA) program was used to analyse our data, continuous variables were shown as mean \pm standard deviations and for categorical variables, percentage and the number of case were used.

\section{Results}

There were 53 cases who underwent total thyroidectomy. The indications of surgery were bilateral multinodular toxic or non toxic goiter in 49 cases and 4 cases of recurrence after subtotal thyroidectomy. The mean age was 47 years for all patients. The youngest patient was 24 years and the oldest was 70 years. There were 47 (88.68\%) females and 6 (11.32\%) males. Among the patients 37 (69.81\%) were presented euthyroidism and 16 (30.19\%) were presented hyperthyroidism. The features of patient's age, gender, diameter of goiter, duration of stay in hospital and indication of surgery were noted in Table 1. Figure 1: shown case of bilateral multinodular goiter 
in this study.

Hematoma developed in one case while wound site infection developed in one patient. Recurrent laryngeal nerve (RLN) palsy occurred in 2 (3.77\%) cases. All RLN palsy cases were unilateral. Permanent palsy was not documented in this study in the postoperative period, hypocalcemia developed in 4 (7.55\%) cases. Whereas no persistent hypocalcemia was observed after total thyroidectomy. We were also registered in postoperative period one case in hematoma and one case in wound infection. We have founded 3 (6.25\%) cases of malignant tumors in the postoperative anatomopathological report. No other complications were noted in postoperative. The postoperative complication rates are shown in Table 2.

\section{Discussion}

Multinodular goiter is a common condition in women, and it is the most represented form of goiters [1]. Bilateral multinodular goiter in our study was the main indication for total thyroidectomy, it's was often associated with the large diameter of goiter or compression signs. For the selected cases, the decision for total excision is sometimes taken during surgery due to the absence of macroscopically normal tissue from the thyroid gland; the patient is informed of this possibility preoperatively. Before the 20th century total thyroidectomy was an intervention reserved for cases of thyroid cancer and benign thyroid pathology for rarely because of the high rate of postoperative complications [8]. Currently it is the standard treatment for toxic or non-toxic multinodular goiter. The most feared complications are among the other recurrent nerve palsy, hypocalcemia can be transient or permanent and also postoperative hematoma [3] [4] [9]. The recurrent nerve palsy is a complication which is related to the experience of the surgeon. In our study we found no permanent recurrent palsy, however, there were $6.25 \%$ transient recurrent nerve palsy. In our practice we insist of identifying recurrent nerve which would significantly reduce the risk of nerve damage. These results are consistent with the literature data that show varying rates between $1.9 \%$ to $4 \%$ [7] [10].

Table 1. Patients’ properties.

\begin{tabular}{llll}
\hline Properties & & Patients $(\mathrm{n}=53)$ & Percentage \% \\
\hline Age & & $47.28 \pm 12.79^{*}$ years & \\
Diameter of goiter & Male & $10.75 \pm 2.85^{*} \mathrm{~cm}$ & 11.32 \\
Gender & 6 & 88.68 \\
& Female & 47 & 92.45 \\
Type of goiter & Bilateral MNG & 49 & 7.55 \\
& Unilateral MNG & 4 & 69.81 \\
& Euthyroidism & 37 & 30.19 \\
\hline
\end{tabular}

${ }^{*}$ Mean \pm standard deviation.

Table 2. Postoperative complications.

\begin{tabular}{llll}
\hline Chirurgical features & & Patients (n= 53) & Percentage \% \\
\hline Length of stay in hospital & & $4 \pm 1.6$ (days) \\
Wound site infection & & 1 & 1.9 \\
Hematoma & Transient & 1 & 1.9 \\
Hypocalcemia & Transient & 4 & 7.55 \\
Recurrent laryngeal nerve palsy & Hypothyroidism & 2 & 3.77 \\
Hormonal status six months after opotherapy & Euthyroidism & 4 & 7.55 \\
& Nodular goiter with/without adenoma & 50 & 92.45 \\
Postoperative histopathologic diagnosis & Malignant & 3 & 94.3 \\
& & 5.7 \\
\hline
\end{tabular}

${ }^{*}$ Mean \pm standard deviation. 


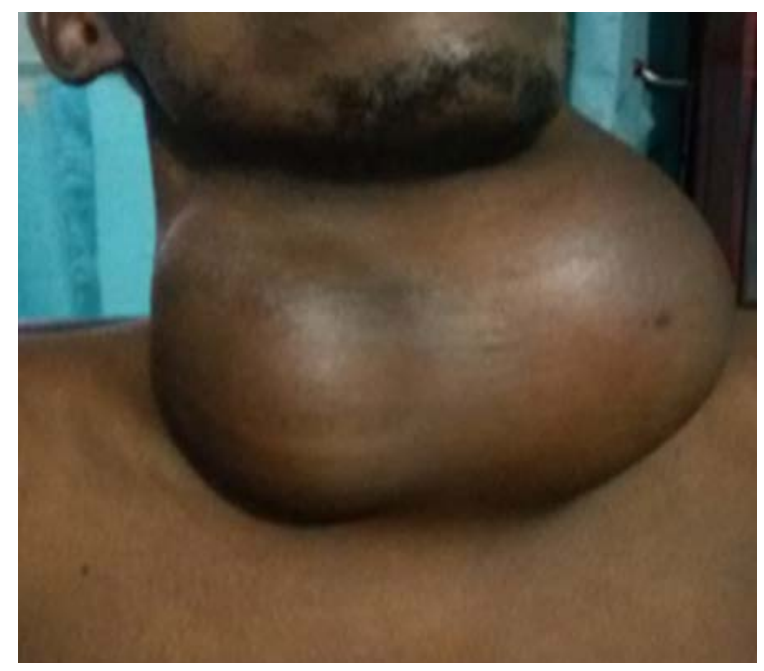

Figure 1. Bilateral multinodular goiter.

The main contributing factors of postoperative transient hypocalcaemia are essentially ischemia parathyroid, postoperative hemodilution and handling of parathyroid can induce an increase in calcitonin secretion. Permanent hypocalcemia is absent in the present study, it is most often linked to accidental parathyroid removal. The transient hypocalcemia rate is in the range of data in the literature ranging from $1.6 \%$ to $20 \%$ [8] [9] [11] [12].

According to the literature, the frequency of postoperative hemorrhage and wound infection ranges between $0 \%$ and 2\% [7] [13] [14]. In our study we were founded similar results, the hematoma was absorbed spontaneously without reoperation and a case of wound site infection was treated by local care. Several studies found no statistically significant difference in complications between total thyroidectomy and subtotal thyroidectomy [7] [10] [15]. The subtotal thyroidectomy is the most practiced in West Africa in the multinodular goiter [5] [6]. The main reasons were the fear of postoperative complications and opotherapy to life and especially of its cost in a country with a high proportion of low income.

However, the recurrence rate is underestimated in these studies that require monitoring over a long period, difficult in our context. Four (4) patients underwent thyroidectomy totalization, indeed it were patients who presented a recurrence of their disease over 10 years after a subtotal thyroidectomy. Better yet we founded 3 (5.7\%) cases of malignant tumors in the postoperative histopathological examination. In the literature the rate is estimated at about 5\% [16]. The discovery of postoperative malignant lesion raises the thorny problem of reoperation, which is lived in our context as a failure of the surgery with the socio-economic repercussions.

Some authors mention the fear of permanent continuity opotherapy lifetime. We think that currently this treatment is no different from the treatment of any chronic pathology that requires treatment for life. Postoperative evaluation of replacement therapy showed that over $90 \%$ of cases were in euthyroid six months after surgery. This good hormonal balance was showed that and anothers studies [17] [18]. The most important factor in decreasing morbidity in thyroid surgery is the surgical technique employed. We think that during the mobilization and dissection of the thyroid lobes, exposing the recurrent laryngeal nerve, employing effective hemostasis during operation to ensure clear operation, viewing parathyroids glands, and protecting their perfusion vessels may help to reduce complications. The mainly limitation of our study were the small size of the sample and the short period of postoperative monitoring.

\section{Conclusion}

Total thyroidectomy for multinodular goiter has a low morbidity and mortality, this procedure that solves both the problem of recurrence of disease and reintervention. The opotherapy is doable with a good hormonal balance. Comparative studies on larger samples are needed to improve the indications of thyroidectomy in our pratice.

\section{References}

[1] Francis, S. and Green, S. (1991) Endocrine Disorders. Medical Clinics of North America, 75, 195-206. 
[2] Bononi, M., De Cesare, A., Atella, F., Angelini, M., Fierro, A. and Fiori, E. (2000) Surgical Treatment of Multinodular goiter: Incidence of Lesions of the Recurrent Nerves after Total Thyroidectomy. International Surgery, 85, 190-193.

[3] De Roy van Zuidewijn, D.B., Songun, I. and Kievit, J. (1995) Complications of Thyroid Surgery. Annals of Surgical Oncology, 2, 56-60. http://dx.doi.org/10.1007/BF02303703

[4] Lombardi, C.P., Raffaelli, M. and De Crea, C. (2007) Complications in Thyroid Surgery. Minerva Chirurgica, 62, 395408.

[5] Touré, A., Diallo, A.T., Camara, L.M., Touré, F.B. and Camara, N.D. (2006) La chirurgie thyroidienne: Experience du service de chirurgie générale du CHU Ignace Deen de Conakry. Mali Médical, 21, 24-27.

[6] Sanogo, Z.Z., Koïta, A.K., Koumaré, S., Saye, Z., Keïta, S., Camara, M., Doumbia, D., Ouattara, M., Togo, S., Yéna, S. and Sangaré, D. (2012) Prise en charge chirurgicale des goitres hyperthyroidiens à Bamako. Mali Médical, 26, 1-4.

[7] Ozbas, S., Kocak, S. and Aydintug, S. (2005) Comparison of the Complications of Subtotal, Near Total and Total Thyroidectomy in the Surgical Management of Multinodular Goiter. Endocrine Journal, 52, 199-205. http://dx.doi.org/10.1507/endocrj.52.199

[8] Alimoglu, O., Akdag, M. and Sahin, M. (2005) Comparison of Surgical Techniques for Treatment of Benign Toxic Multinodular Goiter. World Journal of Surgery, 29, 921-924. http://dx.doi.org/10.1007/s00268-005-7767-3

[9] Bhattacharyya, N. and Fried, M.P. (2002) Assessment of the Morbidity and Complications of Total Thyroidectomy. Archives of OtolaryngologyHead \& Neck Surgery, 128, 389-392. http://dx.doi.org/10.1001/archotol.128.4.389

[10] Ciftci, F., Sakalli, E. and Abdurrahman, I. (2015) Total versus Bilateral Subtotal Thyroidectomy for Benign MultiNodular Goiter. International Journal of Clinical and Experimental Medicine, 8, 4596-4600.

[11] Godazandeh, G., Kashi, Z., Godazandeh, F., et al. (2015) Influence of Thyroidectomy on Postoperative Serum Calcium Level Regarding Serum Vitamin D Status. A Prospective Study. Caspian Journal of Internal Medicine, 6, 72-76.

[12] Koyuncu, A., Dökmetas, H.S. and Turan, M. (2003) Comparison of Different Thyroidectomy Techniques for Benign Thyroid Disease. Endocrine Journal, 50, 723-727. http://dx.doi.org/10.1507/endocrj.50.723

[13] Tezelman, S., Borucu, I., Senyurek Giles, Y., Tunca, F. and Terzioglu, T. (2009) The Change in Surgical Practice from Subtotal to Near-Total or Total Thyroidectomy in the Treatment of Patients with Benign Multinodular Goiter. World Journal of Surgery, 33, 400-405. http://dx.doi.org/10.1007/s00268-008-9808-1

[14] Friguglietti, C.U., Lin, C.S. and Kulcsar, M.A. (2003) Total Thyroidectomy for Benign Thyroid Disease. Laryngoscope, 113, 1820-1826. http://dx.doi.org/10.1097/00005537-200310000-00030

[15] Siragusa, G., Lanzara, P. and Di Pace, G. (1998) Subtotal Thyroidectomy or Total Thyroidectomy in the Treatment of Benign Thyroid Diseases. Our Experience. Minerva Chirurgica, 53, 233-238.

[16] Sanjeeva, K.K., Chandra, B., Balakrishna, M.A., et al. (2015) Clinico-Epidemiological Study and Treatment Outcome of Multinodular Goitre at a Tertiary Care Hospital. Journal of Clinical and Diagnostic Research, 9, 22-25.

[17] Uccheddu, A., Cois, A. and Licheri, S. (1996) The Choice of the Intervention in the Surgical Treatment of Nontoxic Diffuse Multinodular Goiter. Minerva Chirurgica, 51, 25-32.

[18] Rodier, J.F., Strasser, C. and Janser, J.C. (1990) Thyroid Function after Thyroidectomy for Benign Goiter. 200 Cases Explored by Ultrasensitive TSH. Journal de Chirurgie (Paris), 127, 445-451. 